\title{
Estrategias de acompañamiento virtual en un grupo de teatro inclusivo durante tiempos de distanciamiento social
} Virtual follow-up strategies in a Theatre Group in times of Social Distancing

\section{Estratégias para o acompanhamento virtual em um grupo de teatro inclusivo durante tempos de distanciamento social}

\author{
Alicia María Sandoval Poveda \\ Universidad Estatal a Distancia \\ San José, Costa Rica \\ asandovalp@uned.ac.cr \\ (1D https://orcid.org/0000-0002-9678-7586 \\ Linda María Madriz Bermúdez \\ Universidad Estatal a Distancia \\ San José, Costa Rica \\ Imadriz@uned.ac.cr \\ (D) https://orcid.org/0000-0003-2079-3987
}

Recibido - Received - Recebido: 24 / 07 / 2020 Corregido - Revised - Revisado: 18 / 09 / 2020 Aceptado - Accepted - Aprovado: 23 / 09 / 2020

DOI: https://doi.org/10.22458/ie.v22iespecial.3215

URL: https://revistas.uned.ac.cr/index.php/innovaciones/article/view/3215

\begin{abstract}
Resumen: La situación de pandemia producida por el virus de la COVID19 y las subsecuentes medidas de distanciamiento social implementadas para evitar el rápido contagio y colapso de servicios de salud han resultado en un obstáculo para el trabajo presencial de equipos como el Grupo de Teatro Inclusivo Rompecabezas. Este es un proyecto centrado en el desarrollo de habilidades sociales para personas en situación de discapacidad. Este grupo ha buscado en la virtualidad un espacio de acompañamiento emocional para afrontar la ansiedad producida por toda esta situación. El presente artículo expone las estrategias y herramientas de trabajo desarrolladas para este fin, las cuales han sido valoradas por las personas participantes a través de encuestas de percepción a lo largo de la realización semanal de sesiones sincrónicas por tecnología digital y un grupo de chat de mensajería instantánea durante cuatro meses de trabajo en las que han participado los quince integrantes permanentes del grupo. Se presenta una medida subjetiva de ansiedad que muestra cómo a lo largo de las semanas la ansiedad de las persnas participantes ha ido en aumento. Al valorar las herramientas de acompañamiento virtual aplicadas, la apreciación ha sido positiva, tanto para los encuentros virtuales como para el grupo de chat. Además, los participantes y sus familias han señalado el espacio virtual como provechoso para hablar de sus emociones y aprender con respecto a medidas para afrontar la pandemia. Por lo anterior el acompañamiento virtual parece ser una opción viable y funcional en tiempos de pandemia para la población en situación de discapacidad.
\end{abstract}

Palabras claves: situación de discapacidad, pandemia, acompañamiento emocional, distanciamiento social, acompañamiento virtual, COVID-19

\begin{abstract}
The pandemic's situation due to the COVID-19 virus and subsequently implemented measures of social distancing to prevent the spread, and the collapse of the Health Services became an obstacle for in-person teamwork such as the one carried out by the Group of Inclusive Theatre: Rompecabezas. The core of this project is the development of social skills for people with disabilities. Therefore, this group has recently been trying to find in the confines of virtuality an emotional accompaniment arena in order to cope with the anxiety produced by this situation.
\end{abstract}


This article displays both the work tools and the strategies developed for the purpose above. These tools and strategies have been assessed by the group's participants through perception surveys during a week of digital synchronic sessions. Our methods were also assessed through conversations on the group's Whatsapp chat for four months- the fifteen permanent members of the group participated. A subjective measure of anxiety shows how the anxiety of the participants has increased over the weeks. When evaluating the virtual support tools applied, the appreciation has been positive for the virtual meetings and the chat group. Besides, participants and their families have identified the virtual arena as a helpful tool for talking about their emotions and learning how to cope with the pandemic. Therefore, the virtual follow-up seems to be a viable and functional option in pandemic times for the population with disabilities.

Key Words: people with disabilities, pandemic, emotional accompaniment, social distancing, virtual follow-up, COVID-19

Resumo: A pandemia produzida pelo vírus da COVID19 e as subsequentes medidas de distanciamento social implementadas para evitar a rápida disseminação e colapso de serviços de saúde resultaram em um obstáculo ao trabalho presencial de equipes como o Grupo de Teatro Inclusivo Rompecabezas. Este é um projeto voltado para o desenvolvimento de habilidades sociais para pessoas com deficiências. Este grupo buscou na virtualidade um espaço de acompanhamento emocional para enfrentar a ansiedade produzida por toda esta situação. O presente artigo apresenta as estratégias e ferramentas de trabalho para este fim, que foram avaliadas pelas pessoas participantes através de enquetes de percepção durante as sessões sincrônicas semanais de tecnologia digital e um grupo de bate-papo de mensagens instantâneas durante quatro meses de trabalho, no qual os quinze integrantes permanentes do grupo participaram.É apresentada uma medida subjetiva de ansiedade que mostra como a ansiedade das pessoas participantes aumentou ao longo das semanas. Ao avaliar as ferramentas de acompanhamento virtual aplicadas, a apreciação tem sido positiva, tanto para os encontros virtuais quanto para o grupo de bate-papo. Além disso, os participantes e suas famílias apontaram que o espaço virtual foi útil para falar sobre suas emoções e aprender sobre medidas para lidar com a pandemia. Portanto, o acompanhamento virtual parece ser uma opção viável e funcional em tempos de pandemia para a população em uma situação de deficiência.

Palavras-chave: pessoas com deficiência, pandemia, acompanhamento emocional, distanciamento social, acompanhamento virtual, COVID-19

\section{INTRODUCCIÓN}

El virus responsable del Corona Virus Disease 2019 (COVID-19) es altamente infeccioso, con riesgo de complicaciones serias por las que una de cada cinco personas puede ser hospitalizadas por su infección (Organización Mundial de la Salud, 2020). El 11 de marzo de 2020, la Organización Mundial de la Salud (OMS) declaró la enfermedad causada por este virus como una pandemia global y el Ministerio de salud de Costa Rica hizo énfasis en la necesidad de tomar acciones comprometidas por parte de los ciudadanos para desacelerar la propagación del virus ("Todos debemos contribuir", 2020).

De esta manera, la propagación de esta enfermedad en el mundo irrumpió en la vida de todas las personas, obligando a hacer cambios sustanciales en la manera de trabajar, descansar y relacionarse con otros. El trabajo de los grupos artísticos y el desarrollo de procesos pedagógicos o de investigación no estuvieron exentos de estos cambios. Uno de estos grupos, fue el Grupo de Teatro Inclusivo Rompecabezas.

Este grupo realiza su trabajo en el marco del proyecto de desarrollo de habilidades sociales para jóvenes en situación de discapacidad a través del teatro, el cual se desarrolla desde la carrera de Educación Especial de la Universidad Estatal a Distancia de Costa Rica (UNED) desde el año 2016. Este proyecto se desarrolla en la Academia de actuación del Teatro La Máscara, con la participación de jóvenes del Gran Área Metropolitana en talleres semanales donde aprenden actuación y preparan el montaje de obras. En este grupo, participan jóvenes con situaciones de discapacidad como trastorno del espectro autista (TEA) y síndrome de Down, así como voluntarios sin situaciones de discapacidad y profesionales de diferentes áreas como educación, psicología y comunicación.

Según acuerdo del Consejo de Rectoría de la UNED (CR-2020-0437, 2020), una medida preventiva como parte de las medidas de contingencia ante el virus responsable de la COVID-19 fue suspender las 
actividades presenciales. En el caso del Grupo de Teatro Rompecabezas, sus talleres semanales se vieron suspendidos por las medidas de contingencia implementadas ante la situación de la pandemia. El grupo dejó de tener contacto semanal presencial, lo que cortó la interacción entre sus participantes y limitó la misma a las conexiones previas entre algunos de ellos por medio de redes sociales.

Esta situación provocó que el grupo no pudiera reunirse ni continuar con el montaje de su sexta obra de teatro. La medida fue comprendida por las familias, sin embargo, conforme se extendieron las semanas diferentes miembros del grupo se pusieron en contacto por vía de servicios de mensajería instantánea o llamadas telefónicas para manifestar que extrañaban y necesitaban las sesiones en el teatro, así como experimentaban ansiedad por no salir de casa como antes. Ante este panorama, se decidió gestionar una serie de actividades para brindar acompañamiento y mantener abiertos los canales de comunicación para las personas integrantes.

El acompañamiento virtual diseñado respondió tanto a esta necesidad manifestada como a indicaciones brindadas por las autoridades encargadas del tema de atención a la discapacidad. Según la Relatora Especial sobre los derechos de las personas con discapacidad del Consejo de los Derechos Humanos de la Organización de las Naciones Unidas, debe proporcionarse a las personas con discapacidad la orientación adecuada ante la actual pandemia (Devandas, 2020).

La Alianza Internacional de Discapacidad también formuló una serie de recomendaciones, como brindar información sobre la pandemia de forma eficaz y comprensible; demostrar solidaridad ante el miedo y ansiedad generados por las medidas de confinamiento y la crisis provocada por la pandemia y garantizar los servicios de apoyo, accesibilidad y comunicación para las personas en situación de discapacidad ("Hacia una respuesta inclusiva", 2020).

Esta población puede presentar mayores condiciones de vulnerabilidad ante una enfermedad como la COVID-19. Tal y como lo explica Morales (2020), el aislamiento social y la ruptura de las rutinas tienen un impacto emocional que puede generar comportamientos disruptivos. Esto se agrava con la presencia de ansiedad, dificultades para expresar las emociones, sentimientos depresivos e irritabilidad.

Ante estas dificultades que debe afrontar la población, deben acelerarse los esfuerzos para planificar una respuesta diligente, creativa e innovadora para asegurar la atención completa y pertinente de las personas en situación de discapacidad, encontrando estrategias inclusivas para evitar que por su condición se encuentren sin el mismo acceso que las demás personas al sistema de salud, la información, la asistencia médica o de otros profesionales o a la adquisición del virus (Armigate y Nellums, 2020). Según Qi y Fu (2020). La falta de perspectiva sobre la discapacidad en la legislación para atender la emergencia causó serios problemas en la atención de la pandemia en China. Berger, Evans, Phelan y Silverman (2020) señalaron la importancia de una comunicación de la información diseñada para ser accesible de manera transparente, directa y clara para todas las poblaciones.

Sin embargo, los principales trabajos de investigación que pueden encontrarse hasta la fecha con la población se refieren a necesidades identificadas o no satisfechas por los diferentes sistemas de atención a personas con discapacidad ante la pandemia, y no a acciones concretas de atención o estrategias de trabajo con la población durante esta época. Algunas de las necesidades identificadas se presentan a continuación.

Tosseb et al. (2020) señalaron que las medidas de distanciamiento social presentan dificultades particulares para la infancia que presenta barreras para el aprendizaje y sus familias. En un estudio donde enviaron un cuestionario a familias de personas con necesidades educativas especiales, $81 \%$ de ellas personas con trastorno del espectro autista, encontraron que cuando había situaciones de salud mental preexistentes estas se habían exacerbado por el cambio repentino en la rutina. Además, las personas encargadas tenían mayor inseguridad en cómo apoyar de manera apropiada el proceso de aprendizaje de estudiantes que habitualmente trabajaban con un docente especializado. 
Entre las necesidades identificadas, encontraron ofrecer apoyo remoto y asegurar el acceso a formación por parte de personas que reconocen. También incluyeron que las actividades planeadas contemplaran las capacidades y necesidades de cada quién y contar con materiales, equipo físico o aplicaciones virtuales para ayudar a cubrir las necesidades sensoriales. Otras necesidades señaladas, fueron reestablecer rutinas, apoyo emocional para superar la ansiedad y establecer nuevas rutinas (Tosseb et al, 2020).

Según Asbury et al. (2020), las familias con menores en situación de discapacidad y/o barreras para el aprendizaje reportaron que tanto progenitores como descendientes presentaban experiencias de pérdida, preocupación, cambios de humor y cambios conductuales a causa de los cambios sociales relacionados con la situación de pandemia. Se encontró un aumento de ansiedad, estrés y miedo en los niños y niñas, así como ansiedad y estrés en adultos.

De igual forma, Courtenay (2020) señaló como un reto que ha sido posible identificar desde los servicios de psiquiatría y salud mental mantener a personas con trastorno del espectro autista o algún tipo de discapacidad cognitiva en aislamiento o distanciamiento social. De acuerdo con su observación, su condición también implica retos de acceso a la información sobre el funcionamiento del virus, riesgo de agitación y estrés, así como problemas conductuales ante la dificultad de tolerar cambios en la vida cotidiana. Por esta razón, insistió en la importancia de colaboración desde otras instancias que ofrezcan servicios de apoyo para disminuir el impacto de los cambios ambientales producidos por la pandemia.

De acuerdo con el informe australiano de Dickinson y Yates (2020) sobre el impacto de la pandemia en las vidas de familias con menores de edad en situación de discapacidad, estas percibieron que no hay información dirigida a ellos. Su salud mental se había visto afectada con situaciones como ansiedad en menores de edad y habían sufrido la cancelación de citas y servicios para atender su condición. En el ámbito educativo había preocupación tanto por exponer a los jóvenes a adquirir el virus si regresaban las clases presenciales como a que el aprendizaje en casa no fuera suficiente y se diera un retroceso en sus habilidades adquiridas en el contexto escolar. Además, se planteó que no todos lograban aprovechar las consultas o clases en línea.

La mayor parte de publicaciones científicas hasta la fecha se centraron, por tanto, en identificar necesidades que no estaban siendo satisfechas o que debían abordarse con las personas en condición de discapacidad. Propiamente sobre intervenciones lo que fue factible encontrar eran recomendaciones de cómo realizar el abordaje, sin información recopilada de las aplicaciones de experiencias concretas.

Ante esta coyuntura fue necesario plantearse de qué manera se puede brindar un acompañamiento a personas en situación de discapacidad que llenara las necesidades generadas por la situación de pandemia, tales como vías nuevas de comunicación, información accesible y habilidades de afrontamiento. También se volvió relevante encontrar estrategias para mantener los vínculos sociales y las habilidades de interacción sin el contacto directo entre personas.

Los antecedentes de trabajo en intervenciones en situaciones de distanciamiento social fueron pocos. Según Pellicano y Stears (2020), en los próximos meses la investigación relacionada con personas con autismo tendrá que indagar cómo enfrentar los nuevos retos que la pandemia presenta, mientras que en algunos países ya se estaban realizando esfuerzos para brindar apoyo virtual a través de servicios brindados por medio de videotecnología. Experimentar diferentes maneras de brindar servicios a distancia podría mejorar las prácticas que se han venido realizando previamente. Además, deben vigilarse los efectos que el confinamiento y otras medidas pueden tener a nivel de salud mental en las personas con TEA.

De acuerdo con Sherrin (2020), la lucha contra la pandemia está en continuo desarrollo, y en ella se ha podido encontrar familias, voluntarios y personal que trabaja con personas con discapacidad de tipo cognitivo buscando formas creativas e innovadoras de dar continuidad y una sensación de normalidad a las personas con las que conviven y trabajan. 
Una de estas guías es la de Valdés et al. (2020) generada por la Facultad Latinoamericana de Ciencias Sociales (FLACSO), en la cual se presentan ocho estrategias para seguir con las personas con TEA durante la pandemia, las cuales se resumen a continuación:

- Ayudar a comprender: con recursos adecuados a la capacidad de comprensión de cada persona, explicar el virus y las medidas de prevención.

- Ayudar a expresarse: realizar actividades para expresar cómo se sienten. Pueden ser historias, role play, juegos compartidos.

- Promover habilidades de afrontamiento y relajación: ubicar estrategias de relajación para cada persona, como ejercicios físicos, de respiración o escuchar música.

- Mantener rutinas: mantener la programación diaria lo más similar posible a la que siempre ha utilizado.

- Crear nuevas rutinas: incluir nuevas actividades para ocupar el tiempo libre que fomenten su autonomía y capacidad de elección.

- Promover relaciones sociales a distancia: potenciar las posibilidades de comunicación por medios digitales.

- Estar atentos a los cambios de comportamiento: observar si hay cambios de comportamiento que afecten a la persona para contactar a un profesional si esto sucede.

- Cuidar a los cuidadores: los cuidadores también deben cuidar de sus propias emociones y salud durante la pandemia (Valdés et al., 2020).

Hume et al. (2020), desde el Instituto de Desarrollo Infantil UNC Frank Porter Graham, propusieron otras siete estrategias:

- Ayudar a comprender: utilizar herramientas gráficas y con un lenguaje directo. Pueden utilizarse narrativas o señales visuales de apoyo para las explicaciones.

- Ofrecer oportunidades de expresión: se pueden hacer actividades de escritura, obras de teatro, hacer diarios en videos, canciones, baile, yoga y artes visuales.

- Priorizar habilidades de relajación y afrontamiento: usar aplicaciones para guiar la respiración y la relajación.

- Mantener rutinas: mantener las horas de dormir y levantarse, integrarse en las rutinas de limpieza de la casa. Usar las rutinas existentes para trabajar el tema del la pandemia y las emociones de la crisis.

- Construir nuevas rutinas: ofrecer opciones nuevas, limitar el tiempo utilizando dispositivos de pantalla, crear su espacio de trabajo/estudio cuando es necesario.

- Enriquecer las conexiones de lejos: mantener un apoyo social positivo. Utilizar mensajería instantánea y actividades on-line (Hume et al., 2020).

De acuerdo con estos autores, las personas en situación de discapacidad menores de edad durante la pandemia deben enfrentar el cierre de escuelas y colegios, la incertidumbre, los cambios abruptos en la rutina, la pérdida de contacto con profesores y amigos, y necesitan apoyo especial para adaptarse a las noticias y cambios, también experimentan ansiedad y depresión.

Ante este panorama de necesidades ubicadas por diferentes investigaciones, recomendaciones de trabajo para apoyar a las personas en situación de discapacidad durante la pandemia y un interés evidenciado de 
las personas que conforman el Grupo Rompecabezas de continuar en contacto a pesar de las medidas de distanciamiento, se diseñó la estrategia implementada durante los primeros meses de la pandemia.

El presente artículo tiene por objetivo presentar las estrategias pedagógicas y artísticas utilizadas con el Grupo de Teatro Rompecabezas para brindar acompañamiento al grupo de participantes durante la etapa de distanciamiento social a causa del virus responsable de la COVID-19. Estas estrategias se plantearon con el fin de alcanzar los siguientes objetivos: propiciar canales de comunicación dentro del grupo mientras se mantienen suspendidas las lecciones presenciales de teatro; validar las emociones individuales ante el confinamiento por la pandemia; brindar información para un adecuado afrontamiento de la estrategia de distanciamiento social y favorecer la actividad recreativa de las personas participantes del grupo durante la etapa de distanciamiento social en el país.

\section{MATERIALES Y MÉTODOS}

Las estrategias y herramientas de acompañamiento utilizadas se enmarcaron en un diseño de investigación-acción, tal y como el proyecto de investigación del que forma parte. En la fase de planificación, el área problemática se definió en la evaluación con las familias y las personas participantes de las necesidades que estaban presentándose debido al distanciamiento social durante la pandemia. Se realizó un cuestionario dirigido a todas las familias para evaluar la situación. Según los datos obtenidos, así como una revisión de la literatura de otros grupos afrontando la misma problemática, se planificaron las sesiones de trabajo virtuales con los objetivos mencionados de propiciar canales de comunicación, validar emociones, brindar información sobre el virus que causa la COVID-19 y favorecer la actividad recreativa.

En la fase de acción se ejecutaron las sesiones planificadas de manera sincrónica. Al evaluar el avance de esta fase se añadieron retos asincrónicos para ampliar durante la semana el acompañamiento brindado. Se facilitó que las personas participantes integraran a la propuesta sus propias actividades e intereses.

Para la reflexión sobre el trabajo realizado se recolectaron datos de las apreciaciones de las personas participantes y sus familias, de su gusto por las actividades, los aprendizajes adquiridos en las mismas y sus sugerencias para mejoras. A partir de esta información y el análisis de las sesiones se definieron las conclusiones y recomendaciones recogidas en este artículo.

Para la evaluación en concreto del proceso se utilizó un enfoque cualitativo, aunque se aplicaron técnicas cuantitativas para recoger y analizar algunas de las impresiones de las personas participantes.

Las personas participantes fueron 15 jóvenes en situación de discapacidad entre los 12 y los 28 años, 5 mujeres y 10 hombres. Además, se extendió la invitación a familiares, personas voluntarias del grupo, participantes del equipo de investigación.

La estrategia se enmarcó como un trabajo con el grupo de teatro, pero no enfocado en las artes escénicas, sino en el acompañamiento y el compartir durante la época de crisis. Se realizó así una transición de las sesiones dinámicas, interactivas presenciales a una sesión más guiada por la conversación y las actividades dirigidas de manera virtual.

El principal espacio de trabajo fueron sesiones virtuales, que consistían en encuentros semanales vía una plataforma de videollamada en el mismo horario que los talleres de teatro, viernes a las 5 de la tarde, con una duración de entre una hora y hora y media, según la cantidad de actividades que los propios participantes proponían y la cantidad de personas conectadas. Entre el mes de marzo y julio de 2020 se realizaron once sesiones virtuales.

Aunado a estas actividades, para la tercera semana de trabajo se abrió un grupo de chat en un servicio de mensajería instantánea para mantener el contacto durante la semana y enviarles información 
pertinente a las personas participantes como infografías sobre la prevención de la COVID-19, así como organizar actividades asincrónicas lúdicas para el resto de la semana. En este chat se enviaron 20 retos diferentes con actividades para realizar en casa como disfraces, trabalenguas, gimnasia mental, tomar fotografías de algún tema, videos bailando o actuando, realizar actividades nuevas o compartir algo por lo que están agradecidos.

Para evaluar los avances y la efectividad de las sesiones planteadas, se utilizaron los siguientes instrumentos:

- Encuesta de apreciación: se envió a las familias una encuesta para contestar en conjunto con las personas participantes sobre su apreciación del trabajo realizado. En esta se indagó con una escala de puntuación de uno a cinco qué tanto les habían gustado las sesiones virtuales y las actividades en el chat, si las sesiones les servían para hablar de lo que les sucedía en la semana, aspectos que les gustaban de las actividades y sugerencias para mejorar las actividades. Además, en la primera encuesta, se preguntó qué temas querrían que se incluyeran en las sesiones y en la segunda se incluyó sobre qué temas relacionados con el virus responsable de la COVID-19 habían aprendido en el proceso. La primera encuesta se envió el 5 de mayo, después de cuatro sesiones y la segunda encuesta se envió el 14 de julio, después de once sesiones.

- Escala subjetiva de ansiedad: para brindar herramientas para un adecuado afrontamiento resultaba pertinente tener una idea concreta de la ansiedad manejada por las personas participantes. Por lo tanto, se les pidió la primera semana de sesiones y en cada encuesta de percepción, su valoración subjetiva de ansiedad en una escala Likert de puntuación de 1 a 10, siendo 1 relajado y 10 ansiedad máxima. Esta puntuación, aunque subjetiva, permite medir la percepción de cada persona sobre su propia ansiedad, su aumento o disminución. Se consideró, para efectos de este análisis, por encima de 8 ansiedad alta, entre 4 y 7 ansiedad media y entre 1 y 3 ansiedad baja.

- Observación de las sesiones: cada una de las sesiones fue grabada para su registro y análisis. En cada una se observaron las categorías de participación en las actividades, la interacción, las habilidades para participar en una videollamada y la iniciativa mostrada. En cada sesión hubo dos facilitadoras y al menos otra persona del equipo que observara el desarrollo de esta.

La información obtenida por estos instrumentos se analizó de la siguiente manera. Para la encuesta de apreciación se analizaron las frecuencias de respuesta y los promedios de puntuación otorgados por el grupo a su valoración de las actividades. Para la escala subjetiva de ansiedad se realizó una comparación individual entre puntajes otorgados de manera que pudiera apreciarse si la ansiedad en cada caso había disminuido, mantenido o aumentado. En cuanto a las observaciones, se hizo un análisis de contenido de cada una de las categorías observadas.

\section{RESULTADOS Y DISCUSIÓN}

A través de este trabajo fue posible encontrar formas concretas en las cuales utilizar la modalidad virtual para brindar acompañamiento durante el periodo de distanciamiento social durante la pandemia con la población en situación de discapacidad, lo que facilitó la comunicación, la validación de emociones, el acceso a información y las actividades recreativas como forma de afrontamiento.

Para realizar esto, las sesiones virtuales entre marzo y julio se estructuraron de la forma que se explica en la tabla 1. 
TABLA 1

Actividades realizadas en las sesiones

\begin{tabular}{|c|c|c|}
\hline Actividad & Objetivo de la actividad & Desarrollo \\
\hline ¿Cómo están ustedes? & $\begin{array}{l}\text { Compartir sobre el diario vivir y va- } \\
\text { lidar emociones compartidas en el } \\
\text { grupo. }\end{array}$ & $\begin{array}{l}\text { Cada participante comenta cómo ha estado durante la se- } \\
\text { mana, qué cosas ha hecho y cómo se siente. } \\
\text { Según lo comentado, la moderadora pregunta a los de- } \\
\text { más si han hecho algo similar o han sentido lo mismo }\end{array}$ \\
\hline Calentamiento & $\begin{array}{l}\text { Mantener una rutina, } \\
\text { Propiciar la actividad recreativa } \\
\text { Promover el ejercicio como una me- } \\
\text { dida de autocuidado. }\end{array}$ & $\begin{array}{l}\text { Se realiza una actividad que implique movimiento físico: } \\
\text { - Ejercicios } \\
\text { - Baile } \\
\text { - Estiramiento }\end{array}$ \\
\hline Relajación & $\begin{array}{l}\text { Favorecer herramientas para un } \\
\text { afrontamiento adecuado }\end{array}$ & $\begin{array}{l}\text { Se realizan ejercicios de relajación: } \\
\text { - Respiración guiada } \\
\text { - Relajación Jacobson } \\
\text { - Relajación con enfoque en zonas del cuerpo }\end{array}$ \\
\hline $\begin{array}{l}\text { Recomendaciones ante } \\
\text { la situación de pande- } \\
\text { mia por COVID-19 }\end{array}$ & $\begin{array}{l}\text { Explicar de manera accesible algunas } \\
\text { recomendaciones de manejo emo- } \\
\text { cional o conductual ante la pandemia } \\
\text { Expresar las emociones asociadas al } \\
\text { uso de dichas medidas }\end{array}$ & $\begin{array}{l}\text { Explicación de medidas implementadas durante la } \\
\text { pandemia: } \\
\text { - uso de mascarillas } \\
\text { - nueva normalidad } \\
\text { - burbujas sociales }\end{array}$ \\
\hline $\begin{array}{l}\text { Aportes de las personas } \\
\text { participantes }\end{array}$ & $\begin{array}{l}\text { Favorecer canales de comunicación } \\
\text { sobre gustos e intereses en común. }\end{array}$ & $\begin{array}{l}\text { Las personas participantes presentan algo de su interés } \\
\text { o creación. Pueden ser videos de música o películas que } \\
\text { les gustan, juegos, creaciones propias, cantar canciones } \\
\text { novedades que han adquirido, entre otros. }\end{array}$ \\
\hline Actividades recreativas & $\begin{array}{l}\text { Favorecer la comunicación, la distrac- } \\
\text { ción y la relajación en el grupo }\end{array}$ & $\begin{array}{l}\text { Juegos como Simón dice, gimnasia cerebral, creaciones de } \\
\text { cuentos colectivos, charadas, adivinanzas, entre otros }\end{array}$ \\
\hline
\end{tabular}

Fuente: Elaboración propia (2020).

Además de las sesiones virtuales, se utilizó un chat para enviar actividades cortas con fines recreativos (retos de fotografías o juegos para realizar), actividades para la expresión de emociones (decir por qué cosas estamos agradecidos o las cosas que nos gustan de nuestra casa) e información pertinente para el apoyo durante la pandemia (infografías del Ministerio de Salud o la Caja Costarricense del Seguro Social con su explicación).

Como parámetro para conocer la vivencia de ansiedad durante la época de confinamiento se les pidió una medida subjetiva de ansiedad. Debe tomarse en cuenta que la estrategia no ha sido de corte terapéutico con el objetivo de disminuir la ansiedad, sino pedagógico para acompañar en la vivencia de la época de distanciamiento social.

En esta medida fue posible apreciar que la ansiedad iba en aumento conforme pasaban las semanas, como puede apreciarse en la tabla 2.

TABLA 2

Cantidad de participantes que reportan cada tipo de ansiedad percibida durante las tres consultas realizadas

\begin{tabular}{lcccc} 
& Baja (1-3) & Media (4-7) & Alta (8-10) & NR \\
\hline sesiones - Marzo & $6(40 \%)$ & $5(33,33 \%)$ & $4(26,66 \%)$ & 0 \\
5 sesiones - Mayo & $5(33,33 \%)$ & $5(33,33 \%)$ & $5(33,33 \%)$ & 0 \\
11 sesiones - Julio & $1(6,66 \%)$ & $4(26,66 \%)$ & $8(53,33 \%)$ & $2(13,33 \%)$ \\
\hline
\end{tabular}

Fuente: Elaboración propia (2020). 
Al momento de iniciar las sesiones, $26,66 \%$ de las personas participantes referían ansiedad alta, 33,33\% una ansiedad moderada donde se mostraban con deseo de volver a sus actividades regulares, salir de la casa e ir al teatro, pero no parecían experimentar ansiedad por la amenaza del virus en sí o el distanciamiento social. Finalmente, $40 \%$ no mostraban mayores manifestaciones de ansiedad. Habían notado los cambios en la rutina familiar, pero se habían adaptado a ellos y tenían una rutina establecida de ejercicios, trabajo o estudio.

Sin embargo, cinco semanas después, la mayoría había tenido un incremento de la ansiedad percibida, reportando 33,33\% con ansiedad alta. Seis semanas después, más de la mitad de los participantes, $53,33 \%$, manifestaron una ansiedad alta.

La tendencia en la mayoría fue que la ansiedad aumentara conforme se prolongaban las semanas de distanciamiento social. Este aumento, según el reporte de las familias, podría relacionarse con el largo tiempo de distanciamiento social experimentado, así como el aumento de tareas y actividades en casa. Esto resalta la importancia de seguir buscando recursos para acortar distancias, brindar herramientas de afrontamiento y propiciar el grupo como una red de apoyo en tiempos difíciles, dado que la ansiedad de todo el grupo va en aumento ante la situación nacional de número de contagios, hospitalizaciones y el aumento de tiempo en que deben aplicarse las medidas de aislamiento, estudio y trabajo a distancia.

Las dos encuestas de apreciación de las actividades fueron contestadas por quienes habían asistido al menos a una sesión virtual y habían hecho una o más de las actividades del chat. En la segunda encuesta no se contó con las respuestas de dos participantes que no estuvieron presentes en la mayoría de las sesiones virtuales.

Se les pidió calificar las sesiones virtuales de 1 a 5, con un resultado en ambas encuestas en promedio de 4,5 , siendo la puntuación más alta 5 y la más baja 3. En la primera encuesta $100 \%$ de los participantes respondieron que las sesiones les habían servido hablar de cómo se habían sentido en la semana, en la segunda, dos participantes indicaron que no les había servido para este propósito, lo cual se relaciona con los problemas de conectividad para participar de las sesiones.

Se les pidió señalar dos aspectos que les gustaran de este espacio. Entre ambas encuestas resaltaron los siguientes aspectos: diez personas señalaron que les gusta ver o compartir con sus amistades. Seis dijeron que les gusta participar de las actividades durante la sesión. Cuatro resaltaron la posibilidad de hablar de lo que hicieron en la semana. Dos destacaron poder ver al equipo docente y otras dos poder compartir lo que han hecho en la semana. En una ocasión se mencionó hablar de la pandemia y en otra aprender nuevas formas de comunicación como las videollamadas grupales.

De igual forma, se les pidió puntuar de 1 a 5 qué tanto les gustaba participar en el chat, obteniendo en la primera encuesta un resultado de 4.57, siendo la puntuación más alta 5 y la más baja 2 . En la segunda encuesta, el resultado fue de 4,38. Al pedirles destacar dos cosas que les gustaran del chat, cinco personas mencionaron que las actividades eran divertidas, cuatro que les gustaba ver lo que hacían otros, otras cuatro veces se mencionó hablar con amigos o amigas y compartir. Cuatro veces destacaron las actividades que se plantean como retos. Dos personas señalaron participar y otras dos mandar mensajes. Una destacó recibir comentarios por los retos que realiza.

Se les preguntó también qué otras cosas les gustaría hacer en las sesiones virtuales o en el chat de retos. Las respuestas fueron las siguientes: música, noticias, el teatro en mi vida, mi vida familiar, formas de utilizar las mascarillas y la higiene, habilidades de cada uno, programas y personajes favoritos, curso de fotografía, una noche de talento, temas sociales, práctica de teatro, cuentos, disfraces, recordar las obras en las que han participado, juegos, cantos, tecnología, temas de la obra de teatro y temas de superación.

Propiamente sobre temas de los que han aprendido en las sesiones, diez personas dijeron que respiración y relajación, ocho el concepto de "nueva normalidad", siete el uso de la mascarilla, seis el concepto 
de burbuja social y cinco consejos para evitar la ansiedad. Debe considerarse que podían elegir varias opciones de los temas tratados. Los resultados se presentan en la figura 1.

Figura 1. Gráfico de cantidad de personas que refieren aprendizaje sobre cada tema trabajado sobre el virus responsable de la COVID-19 y su manejo.

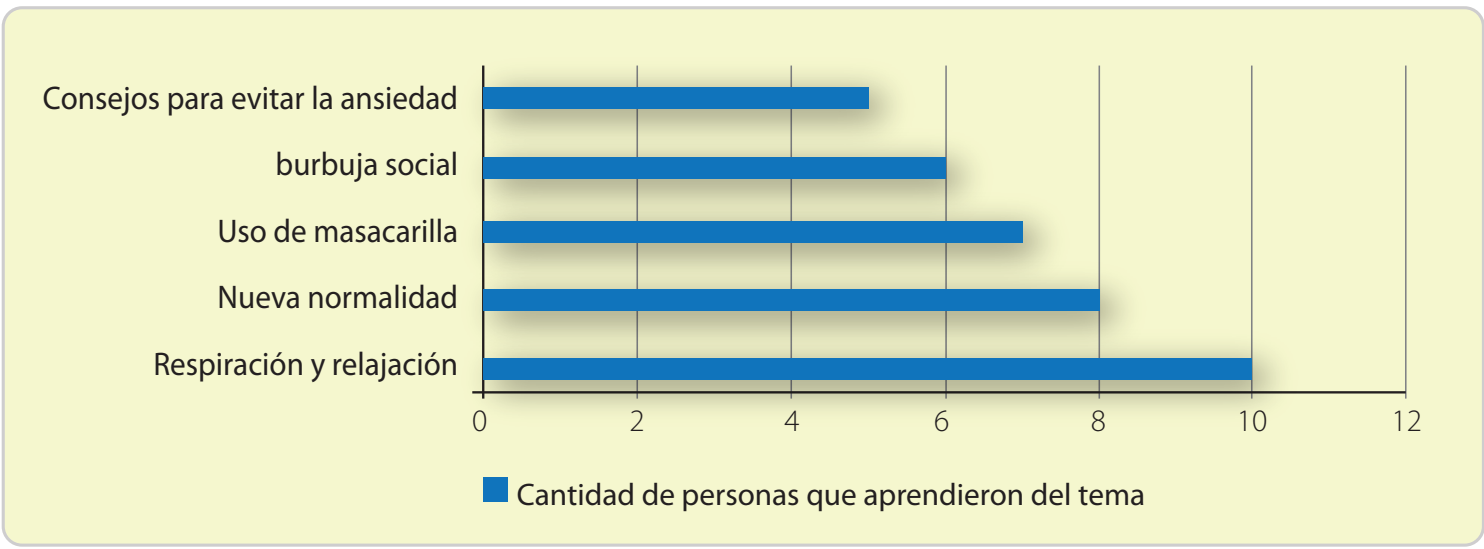

Fuente: Elaboración propia (2020).

En cuanto a recomendaciones o sugerencias para mejorar las actividades se señaló no repetir los videos ni fotografías, decir lo que se piensa, hacer los comentarios de cada participante cortos, utilizar disfraces o cosas artísticas, hablar más de arte, hacer concursos de canciones o baile, hacer las sesiones más largas, aprender más cosas, que haya variedad y participación.

Con respecto a las observaciones realizadas se identificaron varios aspectos a rescatar sobre el acompañamiento virtual realizado. En cuanto a la participación, si bien hay dos participantes que se conectan a la llamada, pero no realizan las actividades, la mayor parte piden la palabra para contar algo, responden las preguntas lanzadas al grupo y realizan las actividades propuestas, incluso hay dos talleristas que participan más en esta modalidad que en la presencial.

En cuanto a la interacción, al inicio de la sesión todas las personas participantes se saludaban entre sí conforme se conectaban a la videollamada. Algunas se hacían preguntas entre ellos y varias traían frente a la cámara algo que quieran enseñar: dibujos que hicieron, comida o bebidas, mascotas, entre otras. En cuanto a habilidades para participar de la videollamada, todo el grupo ha aprendido a abrir y cerrar su micrófono para participar, y se ha mejorado la postura y presentación personal ante la cámara.

Desde el inicio se les ha dado la posibilidad de cada uno llevar contenido a las sesiones y mostrar iniciativa. De esta manera han participado aportando videos de canciones o películas, canto, baile, figuras de colección o juegos que han comprado, mostrando creaciones propias como dibujos, comics o videos e incluso en una ocasión uno de los participantes preparó la actividad recreativa de la sesión, que consistió en adivinar el lugar en el top10 de canciones de Disney en una aplicación de reproducción de música.

La respuesta por parte de las personas participantes, jóvenes y adultos, reflejó que la estrategia cumplió con el objetivo de responder a la necesidad de acompañamiento manifestada al inicio de la pandemia y reafirmada por los diferentes antecedentes de trabajo con la población.

Las sesiones fueron diseñadas para brindar apoyo emocional (Tosseb et al., 2020), brindar información adecuada con las personas participantes que les permita comprender de mejor manera lo relativo a la pandemia y las medidas para protegerse durante esta (Courtnay, 2020; Dickson y Yates, 2020) y brindar herramientas y recursos para afrontar la ansiedad (Asbury et al, 2020; Courtnay, 2020; Morales, 2020). Esta última efectivamente se vio en alza dentro del grupo con el transcurso de la situación de confinamiento, 
pero todas las personas participantes reportaron haber aprendido distintas habilidades que les pueden ser de utilidad para afrontarla.

Toda la estructura de las sesiones y el trabajo virtual realizado ha respondido a las recomendaciones de Valdés et al. (2020) en cuanto a promover las relaciones sociales a distancia (por medio de videollamadas y un grupo de chat), ayudar a expresarse (por medio de actividades y conversatorios en las videollamadas), ayudar a comprender (por medio de explicar infografías y temas sobre la pandemia en las sesiones virtuales), promover habilidades de relajación y afrontamiento (estrategias de relajación y actividades lúdicas) y crear nuevas rutinas (con retos y actividades diferentes a lo que solían realizar).

La respuesta por parte del grupo participante fue positiva, así como las observaciones realizadas de la evolución de las sesiones. Esto valida la utilización de lineamientos como los recomendados por Valdés et al. (2020) y las estrategias planteadas por Hume et al. (2020).

Una situación de crisis como la actual requiere de iniciativas creativas (Sherrin, 2020), característica que ha imperado en la propuesta de trabajo con el grupo Rompecabezas, dado que, aunque se sigan lineamientos generales, la metodología de las sesiones y el trabajo a distancia evolucionaron de manera orgánica con las necesidades e intereses del grupo.

Siguiendo el planteamiento de Pellicano y Stears (2020), el trabajo realizado buscó responder a la necesidad de investigación de encontrar nuevas prácticas que permitan trabajar con la población con discapacidad en un contexto de pandemia como el actual. De esta manera, el trabajo realizado puede ser un aporte a la construcción de estrategias innovadoras e inclusivas (Armigate y Nellums, 2020).

El uso de videollamadas y servicios de mensajería instantánea en este proyecto mostró su utilidad para mantener el contacto y desarrollar el trabajo a distancia, lo que concuerda también con la recomendación de Tosseb et al. (2020) de brindar apoyo remoto, así como lo planteado por Dickson y Yates (2020) en cuanto amoldarse a los medios digitales. El proyecto original al que pertenece el grupo Rompecabezas se centra en las habilidades de comunicación, y esta coyuntura ha forzado el inicio del trabajo con estas habilidades en medios digitales, como la etiqueta y horario para estar en un grupo de chat o cómo encender y silenciar los micrófonos en una videollamada.

De esta manera, se puede apreciar cómo la estrategia realizada responde a los objetivos planteados y al marco de referencia internacional sobre el trabajo con personas con discapacidad durante la situación de pandemia por la COVID-19.

\section{CONCLUSIONES}

Una vez expuesto el trabajo realizado, es necesario resumir cuáles han sido los principales logros y conclusiones a las que se ha llegado tras implementar la estrategia de acompañamiento. Con respecto al objetivo de crear canales de comunicación dentro del grupo, fue posible implementar dos modalidades.

La primera, el grupo de chat, en el cual cada participante envía audios desde su teléfono celular. Aparte de los retos organizados en este canal, envían contenido de su interés y reaccionan al de los demás. El segundo canal fue la videollamada, opción que cada vez más de ellos quiere utilizar, incluso para actividades personales como celebrar su cumpleaños e invitar a las demás personas del grupo. Se concluyó por tanto que ambos canales fueron percibidos por los participantes como útiles y recurren a su uso, tanto dentro como fuera del grupo.

En cuanto al objetivo de validación de emociones individuales, esto se vio manifestado por el acuerdo generalizado de las personas participantes de que pueden hablar de cómo se sienten en las sesiones. Es un espacio seguro y comprensivo, donde se propicia que identifiquen si han experimentado las mismas 
emociones que las demás personas están demostrando, como detestar al coronavirus por no poder salir de casa o el odio al uso de la mascarilla por lo incómoda que es. Además, se abrió en las sesiones el espacio para expresar lo que extrañan de la vida antes de la pandemia, lo que sienten sobre la nueva normalidad y lo que desean para el futuro.

En cuanto al objetivo de brindar información concreta y confiable sobre la pandemia, se cumplió dando especial énfasis a medidas como la burbuja social y la mascarilla en sesión, identificando ideas erróneas y modificándolas, educando sobre su uso y aclarando dudas. Esta información fue bien aceptada y comprendida por las personas participantes, por lo que se manifestó la importancia de crear estos espacios para discutir sobre la información y clarificarla.

Finalmente, en cuanto al objetivo de la actividad recreativa, esta se favoreció desde lo lúdico, con juegos, ejercicio y baile en conjunto durante las sesiones virtuales sincrónicas y con retos en forma de juegos o actividades en la casa, de manera individual o con familiares, de las cuales después compartieron fotos o videos, demostrando así participación e interés. Esto permitió concluir que es posible desde una intervención remota crear nuevas actividades y desde el juego sobrellevar de mejor manera el tiempo de distanciamiento social en los hogares.

De esta manera, se puede observar cómo los cuatro objetivos de trabajo propuestos se cumplieron con la intervención de acompañamiento. Además, fue posible continuar el trabajo de habilidades sociales, objetivo principal del Grupo Rompecabezas, en este caso con habilidades para la comunicación virtual como el manejo de plataformas de videollamada y mensajería instantánea, con el autocontrol en cuanto a esperar su turno de participación en las videollamadas, así como abrir y cerrar el micrófono en su momento de participación y la expresión de emociones en las actividades que así lo propician.

Mientras se mantengan las medidas de distanciamiento social, se continuará con el trabajo de acompañamiento con el grupo ante los resultados obtenidos, manteniendo la misma flexibilidad y apertura a la variación de actividades que se ha tenido hasta ahora, según las necesidades del grupo.

El futuro de los trabajos grupales dentro de la situación de la pandemia es impredecible. Las necesidades de las personas en situación de discapacidad en esta coyuntura tan llena de incertidumbre, ansiedad y limitaciones deben ser monitoreadas con atención, tema que podría profundizarse con más investigaciones en esta línea, en especial desde los grupos que ya estaban trabajando con esta población. Es necesario en futuros proyectos investigativos buscar posibles soluciones, aportes y métodos para hacer más llevadera la situación de distanciamiento social provocada en la actualidad por la pandemia, pero que podría repetirse en futuras circunstancias. De acuerdo con los resultados obtenidos se sugiere profundizar la investigación en la efectividad de metodologías para propiciar canales de comunicación viables y la expresión de emociones a través de plataformas virtuales para personas con dificultades en sus habilidades sociales.

El trabajo descrito en este artículo presenta la manera en que desde el Grupo de teatro inclusivo Rompecabezas se dio respuesta a la situación y pretende aportar la experiencia para ser tomada en cuenta en futuras actividades desde otros grupos ante situaciones de crisis y distanciamiento social como la que se está experimentando en este año 2020.

\section{REFERENCIAS}

Alianza Internacional de Discapacidad (2020). Hacia una respuesta inclusiva de la discapacidad frente al COVID19: 10 recomendaciones de la Alianza Internacional de Discapacidad. Recuperado de http://www.internationaldisabilityalliance.org/sites/default/files/ida_recomendaciones_para_ una_respuesta_inclusiva_de_la_discapacidad_frente_al_covid19.pdf 
Armitage, R., \& Nellums, L. (2020). The COVID-19 response must be disability inclusive. The Lancet Public Health, 5, 257. doi:10.1016/S2468-2667(20)30076-1

Asbury, K., Fox, R., Emze, D., Code, A., \& Tosseb, U. (2020). How is COVID19 affecting the mental health of children with special educational needs and disabilities and their families. Journal of Autism and Developmental Disorders. doi: 10.1007/s10803-020-04577-2

Berger, Z. D., Evans, N. G., Phelan, A. L., \& Silverman, R. D. (2020). Covid-19: control measures must be equitable and inclusive. BMJ (Clinical research ed.), 368, m1141. doi:10.1136/bmj.m1141

Courtenay, K. (2020). COVID-19: Challenges for people with intellectual disabilities. The BMJ, 369, m1609. doi:10.1136/bmj.m1609

Devandas, C. (marzo, 2020) COVID-19: ¿Quién protege a las personas con discapacidad?, alerta experta de la ONU. Naciones Unidas. Derechos Humanos. Oficina del Alto Comisionado. Recuperado de https://www.ohchr.org/SP/NewsEvents/Pages/DisplayNews.aspx?NewsID=25725\&LangID=S

Dickinson, H., \& Yates, S. (2020). More than isolated: The experience of children and young people with disability and their families during the COVID-19 pandemic. Recuperado del sitio de Internet Children and Young People with Disability Australia (CYDA) https://www.cyda.org.au/images/pdf/covid_ report_compressed_1.pdf

Hume, K., Waters, V., Sam, A., Steinbrenner, J., Perkins, Y., Dees, B., Tomaszewski, B., Rentschler, L., Szendrey, S., McIntyre, N., White, M., Nowell, S., \& Odom, S. (2020). Supporting individuals with autism through uncertain times. Chapel Hill, NC: School of Education and Frank Porter Graham Child Development Institute, University of North Carolina at Chapel Hill. Recuperado de https://afirm. fpg.unc.edu/supporting-individuals-autism-through-uncertain-times

Ministerio de Salud (2020). Todos debemos contribuir para proteger a la población más vulnerable ante el COVID-19. Recuperado de https://www.ministeriodesalud.go.cr/index.php/centro-deprensa/noticias/741-noticias-2020/1565-ministro-de-salud-daniel-salas-todos-debemos-contribuir-para-proteger-a-la-poblacion-mas-vulnerable-ante-el-covid-19

Morales, M. (2020). Coronavirus y discapacidad [Edición especial]. Una población muy vulnerable. Acta odontológica venezolana, 58, 9-10.

Organización Mundial de la Salud. (2020). Preguntas y respuestas sobre la enfermedad por coronavirus (COVID-19). Recuperado de https://www.who.int/es/emergencies/diseases/novel-coronavirus2019/advice-for-public/q-a-coronaviruses

Pellicano, E., \& Stears, M. (2020). The hidden inequalities of COVID-19. Autism, 1-2. doi:10.1177/1362361320927590

Qi, F., \& Hu, L. (2020). Including people with disability in the COVID-19 outbreak emergency preparedness and response in China. Disability \& Society, 1-6. doi:10.1080/09687599.2020.1752622

Sherrin, F. (2020). Resilience in challenging times. Journal of Intellectual Disabilities, 24(2), 141-142. doi:10.1177/1744629520926850

Toseeb, U., Asbury, K., Code, A., Fox, L., \& Deniz, E. (2020, April 21). Supporting Families with Children with Special Educational Needs and Disabilities During COVID-19. doi:10.31234/osf.io/tm69k

Universidad Estatal a Distancia (2020). Medidas preventivas ante el COVID-19. Acuerdo de rectoría CR2020-0437. Universidad Estatal a Distancia, Costa Rica

Valdez, D., Manrique, S., Cañote, S., Lazo, C., Canales, C. \& Solcoff, K. (2020). Apoyos a las personas con condiciones del espectro autista y sus familias en tiempos difíciles. Recuperado de https://www. aprendizaje.flacso.org.ar/post/mequedoencasa-apoyo-a-las-personas-con-condiciones-del-espectro-autista-y-sus-familias-en-tiempos 